\title{
Die argumentatiewe funksie van Jakobus 1:9-11 ${ }^{1}$
}

J.L.P. Wolmarans

Dept. Griekse en Latynse Studies

Randse Afrikaanse Universiteit

AUCKLANDPARK
Fika J. van Rensburg

Dept. Ou \& Nuwe Testament

Potchefstroomse Universiteit vir $\mathrm{CHO}$

POTCHEFSTROOM

\begin{abstract}
The argumentative function of James 1:9-11

The connection between James 1:9-1/ and the preceding verses is disputed among commentators. According to the disjointedness hypothesis, there is no connection. Variants of the unitary hypothesis connect 1:9-11 either to 1:2-4 or to 1:5-8. This article proposes a new variant of the unitary hypothesis, namely that 1:9-1I is part of a deductive argument starting at I:2. The author of James wants to prove that believers suffering from poverty should be glad when they suffer, because they will receive everlasting life. He proves this by supplying an instance of modus ponens (1:2-8) as well as an instance of modus tollens (1:9-11). James 1:9-11 is therefore connected to the previous section as a demonstration that the antithesis to the poverty of the oppressed believer is everlasting death.
\end{abstract}

\section{Inleiding}

Jakobus 1:9-11 illustreer in die kleine die problematiek van die Jakobusbrief in sy geheel. Dibelius en Greeven (1981:1-11) het die hipotese gepopulariseer dat die brief nie 'n logiese samehang vertoon nie. Martin (1988:lxvii-lxix) ontwikkel hierdie hipotese deur die geskrif in twee lae te stratifiseer. 'n Grundschrift sou hiervolgens teen 60 n.C. geskryf gewees het, en 'n redaktor sou dit teen 100 n.C. na sy finale vorm verwerk het. Hierteenoor staan navorsers soos Wuellner (1978) en Baasland (1988) wat ' $n$ fyn en netjiese retoriese samehang in die geskrif meen te ontdek.

1 Hierdie artikel is gedeeltelik gegrond op hoofstuk 9 van Wolmarans, J.L.P. 1994. in Semiotiese analise van die Jakobusproloog, ongepubliscerde doktorale proefskrif (Dept. Klassieke en Semitistiek, Potchefstroom : PU vir CHO), voltooi onder die promotorskap van Fika J. van Rensburg. 


\section{Bestaande hipoteses}

\subsection{Die hipotese van onsamehangendheid}

Met die eerste oogopslag wil dit voorkom asof Jakobus 1:9-11 die hipotese vir onsamehangendheid ondersteun. Dit lyk asof tradisionele gegewens oor arm en ryk sonder $\sin$ of rede ingevoeg word. Die vorige verse (1:2-8) handel oor beproewing (1:2-4) asook oor die wyse waarop die gelowige moet bid wanneer hy swaarkry sodat hy korrek kan optree (1:5-8). In die onderhawige gedeelte handel dit onverwags en onvoorspelbaar oor die tema arm en ryk. Dibelius en Greeven (1981:83) merk gevolglik op dat 1:9-11 geen verband met die voorafgaande verse vertoon nie. Die 1983-Afrikaanse Vertaling $(N A B)$ grens dan ook 1:2-8 en 1:9-11 as afsonderlike perikope af.

Die hipotese van onsamehangendheid is egter nie bevredigend nie. Daar kan aanvaar word dat die geskrif bedoel was om in ' $n$ samekoms van gelowiges voorgelees te word - soos ander kerklike geskrifte van daardie tyd. Kolossense 4:16 gee byvoorbeeld ' $n$ opdrag dat, nadat die Kolossensebrief in Kolosse voorgelees is, dit ook na die gemeente van Laodisea gestuur moet word. Dit is dus moontlik om die mondelinge aard van onderrig in die vroeë Christelike kerk te veronderstel.

Kenmerke van literatuur wat hoofsaaklik mondelings versprei is, is dat dit hulp vir die hoorder bevat om dit wat hy/sy hoor, te onthou (Foley, 1986). As aanvaar sou word dat 1:9-11 glad nie met die voorafgaande gedeelte skakel nie, sou dit onmoontlik wees om te verklaar hoedat die Jakobusbrief vrugbaar in 'n mondelinge kultuur kon funksioneer. Die verwagting is dat daar kohesie tussen die verskillende perikope moet wees wat dit vir die hoorders moontlik sou maak om die inhoud te memoriseer of minstens te onthou.

\subsection{Die eenheidshipotese}

Die ondersteuners van die eenheidshipotese vind wel 'n verband tussen 1:9-11 en die voorafgaande. Ropes (1916:144) asook Laws (1980:62), Hoppe (1989:36) en Johnson (1995:191) is van mening dat 1:9-11 'n los voortsetting is van die aanmoediging in 1:2-4 om onder beproewing te volhard.

Die breê tema van 1:2-11 is dus die volharding in beproewing

- van die arm gelowige (1:2-4) en

- van die ryk gelowige as hy sy rykdom verloor (1:9-11).

Hiervolgens handel die tussenstuk (1:5-8) oor gebed, spesifiek oor die gebed om wysheid (as kennis van die regte optrede) wanneer die gelowige beproef word. Die implikasie is dus dat 1:9-11 die spesifieke beproewing van die ryk broer 
onder oë neem, naamlik die verlies van rykdom. Al vergaan sy rykdom, moet die ryk broer getrou bly aan sy geloof.

Hierdie interpretasie berus op die volgende aannames:

- Die term "ryke" (1:10) verwys na 'n gelowige mens wat ryk is;

- die beproewing (vernedering) wat hy ervaar, is die verlies van sy rykdom.

- Selfs onder sulke omstandighede moet hy "spog" of bly wees $(1: 10)$.

Die imperatief aan die ryke om te "spog" (1:10) moet volgens hierdie standpunt letterlik opgeneem word en nie ironies nie.

Dié interpretasie is egter problematies. In die res van die geskrif word die ryk mens nie as 'n gelowige beskryf nie, maar juis as die antitese van die arm en gelowige mens. In 2:1-13 is die arme die protagonis (uitverkies deur God, 2:5) en die ryke die antagonis wat die arm gelowiges verdruk, in die tronk laat gooi (2:6) en wat die Naam van Jesus belaster (2:7). Dieselfde denkstruktuur kom ook voor in 5:1-6. Die rykes word gemaan om te huil oor die ellendes wat oor hulle gaan kom (5:1). Hulle sonde is dat hulle in die laaste dae skatte vergaar het (5:3), die loon van die arbeiders wat hulle lande vir hulle geoes het, teruggehou het $(5: 4)$, en "die regverdige" veroordeel en vermoor het $(5: 6)$. Die oordeel wat hulle gaan tref, is dat hulle goud en silwer sal verroes ( $\kappa \alpha \tau i \omega \tau \alpha$ i profetiese perfektum - 5:3) en dat die roes soos vuur die vleis van die rykes sal verteer. Die bedoeling is dat die roes van die rykdom wat die rykes nie met die armes gedeel het nie, getuienis teen hulle is wat die straf van die helse vuur tot gevolg sal hê (Smith, 1992:88).

As ' $n$ mens dus 1:9-11 interpreteer in die lig van die hele konteks van Jakobus, kan dit nie oor 'n ryk gelowige gaan nie. Dit is verstaanbaar dat kommentatore sou verkies om rykes as deel van die gemeente te beskou, ten einde nie rykes in hedendaagse gemeentes te na te kom nie. Dit is egter nie verantwoord om 'n hedendaagse situasie onkrities in dié teks in te dra nie.

Die vergelyking wat in 1:10-11 gebruik word, is dat die ryke (en nie sy rykdom nie) soos 'n veldblom sal vergaan. In die lig van 5:1-6 kan dit net na die eindoordeel verwys. Dit gaan dus nie in 1:9-11 oor die beproewing wat 'n ryk gelowige kan ervaar nie; dit gaan oor die vernietiging van die arm gelowige se antagonis. Die uitspraak dat die ryke moet "spog" oor sy vernedering is dus ironies bedoel. Die effek van hierdie ironie is dat die geimpliseerde imperatief "spog" teenoorgesteld geïnterpreteer word: die ryke moet huil of treur want hy gaan vernietig word (ook 5:1; Wolmarans, 1983). 
Maynard-Reid (1987:39) aanvaar die interpretasie dat dit hier in 1:9-11 oor die ondergang van die ryk ongelowige handel. Hy stel dan dat 1:9-11 by 1:5-8 aansluit. Volgens hom beweeg die gedagtegang van die generiese (die "dubbelsielige" van 1:8 wat onbestendig in al sy weë is) na 'n spesifieke voorbeeld van só 'n "dubbelsielige" mens, naamlik die ongelowige ryk mens. Hierdie oplossing is ook nie aanvaarbaar nie, aangesien 1:9 begin met 'n verwysing na die arm of nederige broer wat nie direk by 1:5-8 aansluit nie.

Daar bestaan dus basies twee hipoteses oor die verband van 1:9-11 met die vorige verse. Die eerste (onsamehangendheids-) hipotese stel dat daar geen verband is nie. Daar is reeds beredeneer dat hierdie hipotese onaanvaarbaar is. Variante van die tweede (eenheids-) hipotese wil 1:9-11 met 1:2-4 verbind of met 1:5-8. Ook hierdie variante van die hipotese bied nie bevredigende antwoorde nie. Gevolglik kan gevra word of 1:9-11 nie by 1:2-8 in die geheel aansluit nie. Dit sal dan 'n derde variant van die eenheidshipotese wees.

\section{3. 'n Derde variant van die eenheidshipotese}

Verskillende formele faktore dui in die rigting dat hierdie variant van die eenheidshipotese ondersoek en toetsing verdien. Daar is formele bindings tussen $1: 9-11$ en 1:2-4. Die imperatief $\kappa \alpha v \chi \alpha ́ \sigma \theta \omega$ ("laat hy spog") van 1:9 is byna

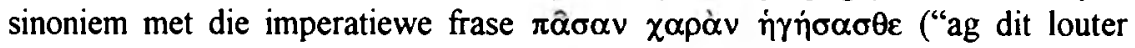
vreugde") van 1:2. Die gebruik van hierdie imperatiewe kan moontlik in die rigting dui dat die tema van blydskap in beproewing (1:2) ook in 1:9-11 verder ontwikkel word.

'n Verdere verband met 1:2 is dat 1:9-10 ook formeel 'n paradoks is. In 1:2 is die paradoks dat die gelowige bly moet wees wanneer hy beproewing ervaar. Die paradoks in 1:9 draai om die feit dat die arme normaalweg oor sy nederige lot huil. Dit is die ryke wat oor sy hoogheid spog (4:16). Nou egter word die arme opgeroep om oor sy hoogheid (verhoging) te spog. Die ryke kan net "spog" omdat hy verneder gaan word.

Daar is egter ook formele bindings tussen 1:9-11 en 1:5-8. Die woord óoố

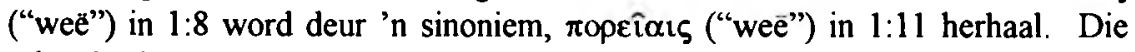
ryke is in Jakobus by uitstek die antagonis van die arme (2:6-7), die "dubbelsielige" (1:8) wat sowel aan die aarde as die hemel verknog wil wees. Die ryke se lewenswyse is gebou op 'n aardse wysheid (3:15) en nie op die hemelse (3:15) een nie. Omdat hy volgens twee beginsels probeer leef (die aardse en die hemelse), is sy lewe onbestendig $(1: 8 ; 3: 16)$ en eindig dit by die ewige dood (1:11). 
Die formele bindings wat daar tussen 1:9-11 en 1:2-8 bestaan, versterk dus die vermoede dat 1:9-11 op die een of ander wyse moet inpas in die argument wat in 1:2 begin.

Op watter wyse word dit egter gedoen? In 1:9 word gestel dat die arme moet "spog" oor sy verhoging, dit is, dat God hom in die hiernamaals 'n besondere plek sal gee. Hoe sluit die eskatologiese vernedering van die ryke egter by die tema van blydskap in beproewing aan?

\section{Insigte vanuit die logika}

Insigte wat deur die dissipline van die logika ontwikkel is, kan help in die oplossing van hierdie probleem. Copi en Cohen (1994) gaan van die standpunt uit dat enige taaluiting ' $n$ logiese onderbou het. Dit is dus geldig om logiese kategorieè te gebruik om taaluitinge te ontleed.

\subsection{Induktiewe en deduktiewe ontwikkeling van argumente}

Oor die algemeen word aanvaar dat argumente basies op twee maniere ontwikkel, naamlik induktief en deduktief. ${ }^{2}$

- Induktiewe ontwikkeling behels dat besondere voorbeelde gegee word en dat 'n afleiding oor hierdie voorbeelde gemaak word in die vorm van 'n algemene stelling. Dit kan skematies as 'n wig voorgestel word.

- Deduktiewe ontwikkeling behels dat 'n stelling aan die begin gemaak word en dat hierdie stelling dan met voorbeelde toegelig word. Dit kan skematies as 'n driehoek voorgestel word.

Kombinasies van deduktiewe en induktiewe argumentasie kom natuurlik ook voor. ${ }^{3}$

\subsection{Toegepas op Jakobus 1:2-11}

As hierdie basiese insigte nou toegepas word op 1:2-11, kan beredeneer word dat die stelling (demonstrandum, dit wat bewys moet word) in 1:2 voorkom, naamlik dat die gelowige rede het om bly te wees wanneer daar allerlei beproewings oor hom kom. In 1:3-4 word die stelling dan deduktief ontwikkel deurdat die beproefde gelowige met onsuiwer metaalerts vergelyk word. Hierdie erts kan net

2 Vergelyk byvoorbecld Copi en Cohen (1994) vir 'n volledige bespreking van induksie, deduksie en die verhouding tussen taal en logika.

3 Vergelyk Wolmarans en Van Rensburg (1987:39-41) vir 'n bespreking van die sogenaamde sandloper- en diamantmodelle. 
deur beproewing gesuiwer word (sien Wolmarans, 1991 vir 'n beskrywing van die logiese struktuur van hierdie analogie).

Die voorwaarde vir 'n gelukkige afloop wanneer ' $n$ mens beproef word, is om in volmaakte werke te volhard (1:4). Wat is volmaakte werke? Dit is werke wat uit wysheid voortkom. Wysheid is 'n gawe van God en vir hierdie wysheid kan daar slegs met geloof gebid word (1:5-8). Die argument tot dusver is dus dat die gelowige slegs 'n gelukkige afloop van sy beproewing kan ervaar indien hy werke doen wat in wysheid verrig word. Dan volg 1:9-11 wat hoofsaaklik die negatiewe afloop gee van die ryke se lewenswyse. Hoe pas dit dan in by die deduktiewe argument wat tot dusver ontwikkel is? Baie eenvoudig.

'n Stelling, soos 1:2, kan in simboliese logika soos volg voorgestel word:

As 'n mens beproef word, kan hy blydskap ervaar $(\mathrm{P} \rightarrow \mathrm{Q})$.

In die konteks van Jakobus 1:2-4 kan hierdie stelling hervertaal word met: As 'n mens beproef word, sal jy ewig lewe. Hierdie stelling kan nou op twee wyses in 'n argument ontwikkel word (sien byvoorbeeld Nolt, 1994:141-180), naamlik deur die argumentatiewe vorm van modus ponendo ponens (bevestig die protasis of antesedent van die voorwaarde), of die argumentatiewe vorm van modus tollendo tollens (ontken die apodosis van die voorwaarde). Albei argumentsvorme is reeds deur die klassieke filosowe beskryf (Copi \& Cohen, 1994:206).

Die modus ponendo ponens-argument (normaalweg afgekort as modus ponens), kan simbolies soos volg voorgestel word:

\begin{tabular}{|ll|}
\hline 1. $P \rightarrow Q$ & [As 'n mens beproef word, verkry jy die ewige lewe] \\
2. $P$ & ['n Mens word beproef] \\
3. Dus $Q$ & [Dus: 'n Mens verkry die ewige lewe]
\end{tabular}

Die voorbeeld wat in 1:3-4 gebruik word, is dat daar 'n analogie tussen die gelowige en metaalerts getrek word. Metaalerts word beproef (fyn gekap, verwarm, gehamer). Die erts word nie deur hierdie beproewing vernietig nie, maar gelouter; dit word onverganklik. Net so gaan dit met mense: as hulle beproef word, word hulle onverganklik. Die voorwaarde hiervoor is om in volmaakte werke te volhard op grond van 'n wysheid wat van God af kom (1:58).

Hiermee kom 1:9-11 wat as die modus tollendo tollens-argumentvorm voorgestel kan word (gewoonlik afgekort as modus tollens) in die fokus: 
1. $\mathrm{P} \rightarrow \mathrm{Q} \quad$ [As 'n mens beproef word, verkry jy die ewige lewe]

2. Nie-Q ['n Mens verkry nie die ewige lewe nie]

3. Dus nie-P ['n Mens word nie beproef nie]

Die voorbeeld wat in 1:9-11 gegee word, is dat 'n mens wat nie beproef word nie (die ryke), nie die ewige lewe verkry nie, maar met die ewige dood gestraf word. Hierdie voorbeeld dien as bevestiging van die stelling in 1:2. Die ryk mens is glad nie soos metaalerts nie, maar analoog aan 'n veldblom. Die beproewing van son en die wind laat die veldblom verwelk. Net so gaan dit met die ryk mens: sy lot is die ewige dood. Die implisiete rede is dat die ryk mens nie in volmakte dade volhard nie. Die funksie van 1:9-11 is dus om op 'n antitetiese wyse die stelling van 1:2 te bevestig: die nie-beproefde word met die ewige dood gestraf. Dit pas dus logies gesproke baie duidelik in by die deduktiewe ontwikkeling van die argument.

\section{Gevolgtrekking}

Hierdie voorbeeld moet die gelowige daartoe bring om nie die profiel van die ryk mens te wil aanneem nie. Die ryke moet nie vir hom 'n rolmodel wees nie. In 1:5 stel Jakobus 'n teologiese premis oor God: "God gee ryklik aan alle mense en Hy verwyt nie." Jakobus het moontlik voorsien dat sy lesers met 'n teenvoorbeeld sou kom: "Hoekom is ons gelowiges dan arm, en die ongelowige rykes leef in oorvloed?" Jakobus 1:9-11 beantwoord hierdie vraag met die volgende: dit wat die ryke besit en ontvang, het geen ewigheidswaarde nie; inteendeel, dit lei tot sy vernietiging.

Dit is dus wel waar dat dit met die ryke voorspoedig gaan; hy ervaar nie die nood en die verdrukking van die arme nie. Vir hom is die uiteinde egter die ewige dood. Die gelowige wat in sy toestand van beproewing in volmaakte werke volhard, en wat gevolglik wys lewe volgens die wysheid wat God gee, sal vir ewig leef.

Hierdie interpretasie van die gedagte-ontwikkeling van 1:2-11 is alleenlik moontlik as 'n mens 'n antitetiese wêreldbeskouing vir Jakobus veronderstel. Die veronderstelde hoorder is die arm gelowige. Sy antitese is die ryk ongelowige. Die hiernamaals staan in kontras met die hiernoumaals en aardse rolle word daar omgekeer. Die arm gelowige wat in die hiernoumaals "vermoor" word (5:6), ontvang die ewige lewe (1:12). Die ryke wat hier op aarde onbesorgd "lewe" sal onder die son van God se geregtigheid verwelk (1:11) en die ewige dood as straf ervaar $(5: 2-3)$. 
Jakobus 1:9-11 is dus 'n kontraposisionele ondersteuning van die demonstrandum (1:2). Dit is dus duidelik dat 1:2-11 in sy geheel ' $n$ baie fyn en netjiese samehang vertoon. Hierdie waarneming ondersteun die eenheidshipotese.

\section{Bibliografie}

BAASLAND, E. 1988. Literarische Form, Thematik und geschichtliche Einordnung des Jakobusbriefes. (In Haase, W. Aufstieg und Niedergang der Romischen Welt. Geschichte und Kultur Roms im Spiegel der neueren Forschung. Teil II: Principat. Band 25 (5. Teilband). Berlin \& New York: Walter de Gruyter. p. 3646-3684.)

COPI, I.M. \& COHEN, C. 1994 . Introduction to logic. ${ }^{9}$ New York : Macmillan.

DIBELIUS, M. \& GREEVEN, H. (hersiener). 1981 James. (Uit Duits vertaal deur $\mathbf{M}$. Williams.) Philadelphia : Fortress Press.

FOLEY, J.M. 1986. Oral tradition in literature: Interpretation in context. Columbia University of Missouri Press.

HOPPE, R. 1989. Jakobusbrief. Stuttgart : Verlag Katholisches Bibelwerk GmbH.

JOHNSON, L.T. 1995. The Letter of James. New York: The Anchor Bible, Doubleday.

LAWS, S. 1980. A commentary on the Epistle of James. London : Adam \& Charles Black.

MARTIN, R.P. 1988. James. Waco, Texas : Word Books.

MAYNARD-REID, P.U. 1987. Poverty and wealth in James. Maryknoll, New York : Orbis Books.

NAB. 1983. Die Bybel. Nuwe Vertáling. Kaapstad : Bybelgenootskap van Suid-Afrika.

NOLT, J.E. 1994. Informal logic. Possible worlds and imagination. New York : McGrawHill.

ROPES, J.H. [1916] 1968. A critical and exegetical commentary on the Epistle of St. James. Edinburgh : Clark.

SMITH, S.M. 1992. Die mensbeeld in die Jakobusbrief. Johannesburg : Randse Afrikaanse Universiteit. (M.A.-verhandeling.)

WOLMARANS, J.L.P. 1983. Towards the interpretation of James 1:9-11. Ekklesiastikos Pharos, 65:27-34.

WOLMARANS, J.L.P \& VAN RENSBURG, J.F.J. 1987. Van lessenaar na preekstoel Psalm 136 en Filippense 3:2-11. Johannesburg : Woordmeesters.

WOLMARANS, J.L.P. 1991. Making sense out of suffering. James 1:2-4. Hervormde Teologiese Studies, 47(4):1109-1121.

WUELLNER, W.H. 1978. Der Jakobusbrief im Licht der Rhetorik und Textpragmatik Linguistica Biblica, 43:5-66. 